\title{
Novel Methods for Detection of Microbes at Cellular and Molecular Level
}

\author{
Noshaba Munawar ${ }^{1}$, Muhammard Jawad Bashir ${ }^{2}$, Waheed Ahmed ${ }^{3}$, Sarfraz Khan ${ }^{2}$, Muhammad Azam ${ }^{2}$, Rimal Ayesha ${ }^{2 *}$, \\ Mahnoor Nadeem ${ }^{1}$ \\ ${ }^{1}$ Department of Zoology, Wildlife and Fisheries, University of Agriculture Faisalabad Pakistan \\ ${ }^{2}$ Institute of Microbiology, University of Agriculture Faisalabad Pakistan \\ ${ }^{3}$ Department of Parasitology and Microbiology, PMAS Arid Agriculture University Rawalpindi Pakistan
}

DOI: $10.36348 /$ sjpm.2021.v06i04.004 | Received: 06.03.2021 | Accepted: 05.04.2021 | Published: 13.04.2021

*Corresponding author: Rimal Ayesha

\section{Abstract}

Bacterial contamination is a growing global public health threat for individuals, food industry, hospital diagnostics and society. While antibiotics can be used to treat most bacterial infections, they constantly accelerate the emergence and spread of resistance bacteria. Today, many antibiotics are ineffective, but the pace of discovery of new antibiotic has dropped substantially. Conventional methods used to detect and quantify bacteria are plate culturing, polymerase chain reaction (PCR), enzyme linked immunosorbent assay (ELISA) and chemical sensors based detection strategies. Molecular based detection method PCR is considered to be another standard method to detect bacteria. This method can be used for bacteria detection with high sensitivity and specificity, but well-trained personnel and costly instrumentations are indispensable. New colorimetric bacteria detection method based on bacterial inhibition of glucose oxidase-catalyzed reaction. The concentrations of microbes access by following the disc diffusion method that using the antibiotics and also discs to differentiate the different strains of bacteria. Bacterial cultures ability grown in petri plates by using the growth medium such as nutrient agar. Methicillin resistant Staphylococcus aureus (MRSA) is detected with excellent specificity and sensitivity by IDI-MRSA via simultaneous targeting of the staphylococcal chromosomal cassettes.

Keywords: Microbes, Enzymes, Cellular biology, Molecular, methods, ELISA, PCR.

Copyright ( $) 2021$ The Author(s): This is an open-access article distributed under the terms of the Creative Commons Attribution 4.0 International License (CC BY-NC 4.0) which permits unrestricted use, distribution, and reproduction in any medium for non-commercial use provided the original author and source are credited.

\section{INTRODUCTION}

Enzyme-linked immunosorbent assay (ELISA) is the enzyme based detection of the antigen or antibody in the particular samples by assisting the diagnosis of diseases in clinical as basic sciences [1-3]. Through ELISA, a variety of antigens or proteins in pathogens, viruses, bacteria can be tested or detected in order to spearing of infections to other tissues as well as to control the diseases rate. An easy and rapid ELISA system, Filtration ELISA to detect antibodies against bacterial cell surface antigens. The variations in ELISA allow us to detect either antigen or antibody, identifying the different strains of microbes at a time and also in characterization of the epitope distribution on the microbial surface $[4,5]$.
ELISA is also used for bacteria detection and considered as one of the most popular immunoassay methods. ELISA may provide results slightly faster compared with plating culturing and PCR, but high false positive and complex experimental operation limit its applications. Furthermore, each of those methods mentioned above has its advantages, but all of them are laboratory-based and unable to be tested on site, which limit their utility for bacteria analysis in daily life practice. The need for improved bacteria detection methods has led to the development of chemical sensors, including colorimetric detection. New colorimetric bacteria detection method based on bacterial inhibition of glucose oxidase-catalyzed reaction $[5,6]$. 


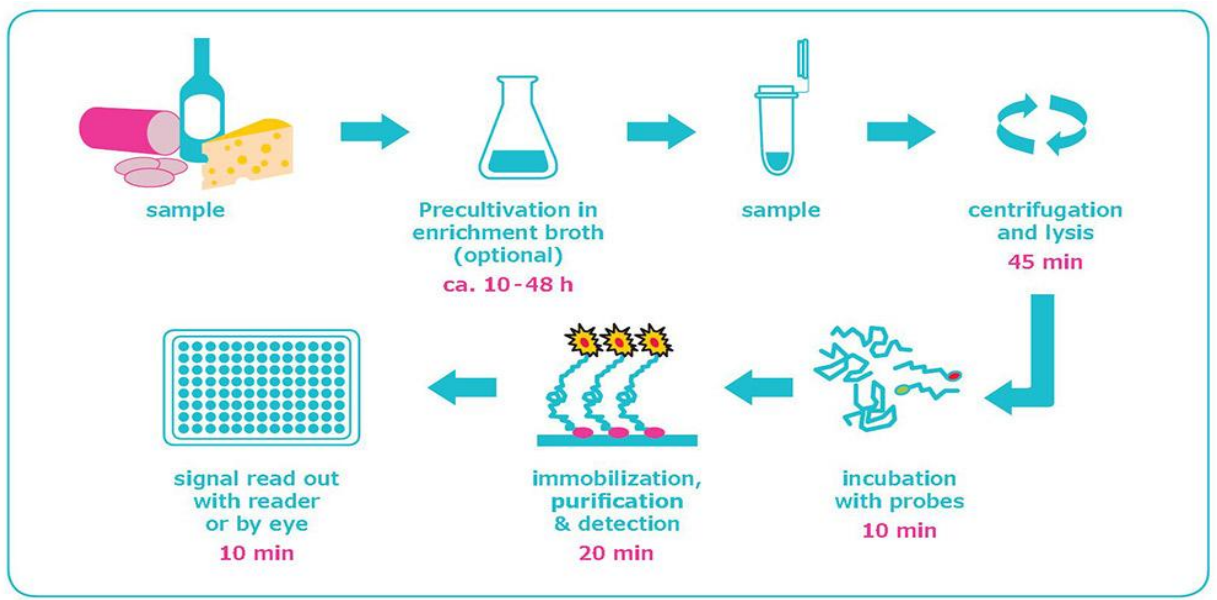

Fig-1: Shows the Quantitative Identification of microorganism in food water

\section{PCR based detection}

The PCR is the most sensitive of the existing rapid methods to detect microbial pathogens in clinical specimens. During the course of a bacterial infection, the rapid identification of the causative agent is necessary for the determination of effective treatment options. Different types of bacterial pathogens can be detected through PCR such as Enterococcus faecalis, Staphylococcus aureus, Staphylococcus epidermidis, and Streptococcus pyogenes. Real-time PCR technology that can monitor the products by measuring the fluorescent signal continuously is most commonly used as a rapid and reliable tool because of its high sensitivity and specificity $[7,8]$.

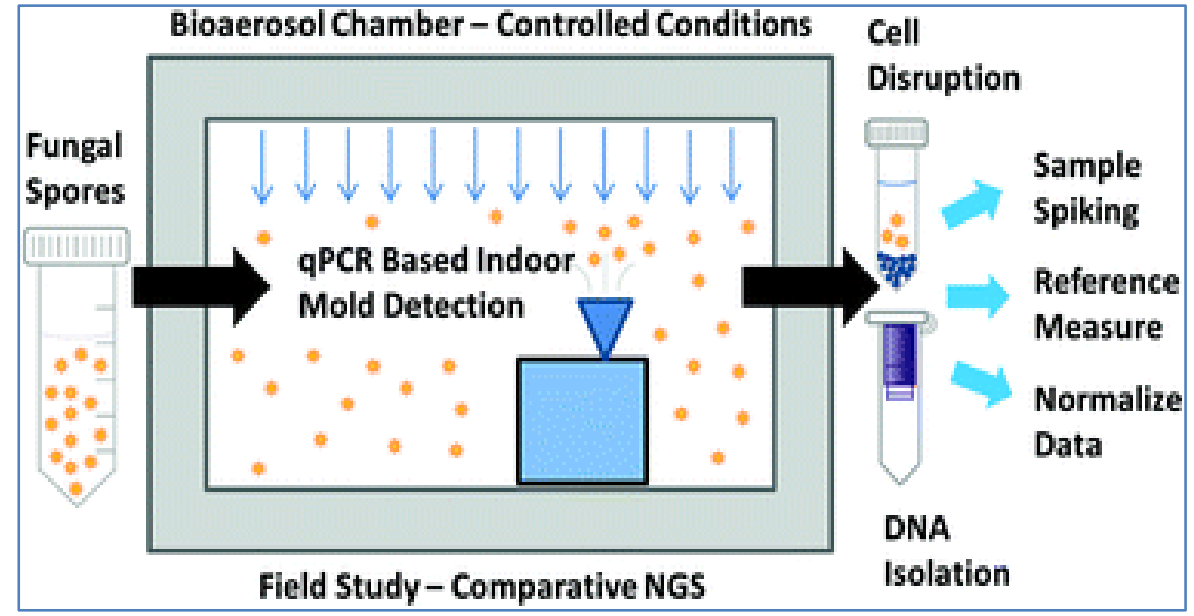

Fig-2: Shows the microbial detection through PCR at molecular level

\section{Colorimetric bacterial detection method}

Glucose oxidase as one of the important enzyme is used for the oxidation of glucose to produce hydrogen glucose. Starch reacts with the iodide though chemical combination and then starch-iodide paper as the substrate reacts with hydrogen peroxide to produce a deep blue color. Glucose metabolism is a common phenomenon for bacteria. With the presence of bacteria, the GOX-catalyzed reaction inhibited due to the lack of glucose, which subsequently influenced the oxidation chromogenic reaction of iodide and starch $[9,10]$.

Disc diffusion method for testing the antimicrobial activity

The concentrations of microbe's ability to determine by following the disc diffusion method that using the antibiotics and also discs to differentiate the different strains of bacteria. Bacterial cultures in this method grow in petri plates by using the growth medium such as nutrient agar. The protocols of this method as follow. For purpose of inoculation, nutrient broth powder in the amount of $13 \mathrm{~g} / \mathrm{L}$ catalysed put to the distilled water, and then mixed both them properly for homogenization. Then medium catalysed passed through the autoclave at temperature of $120^{\circ} \mathrm{C}$ for 20 minutes. Medium catalysed taken from autoclave and suitable bacterial strain catalysed put and mixed properly to medium and placed it to shaker for proper shaking $37^{\circ} \mathrm{C}$ for 24 hours. Inoculate catalysed and obtained and stored at $5^{\circ} \mathrm{C}[11,12]$. 


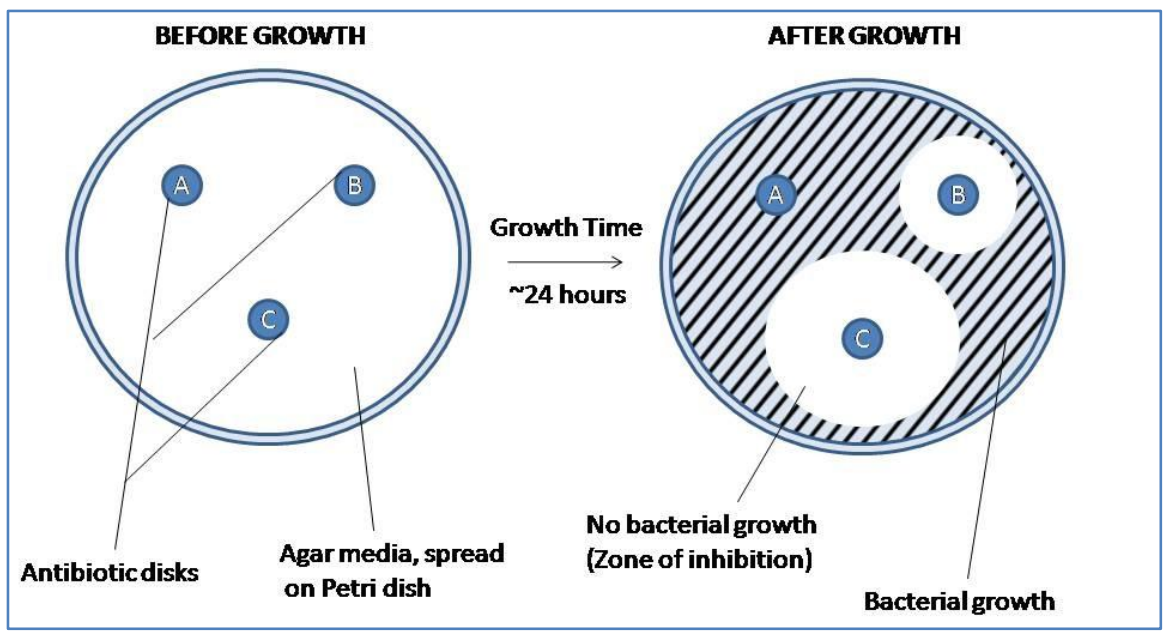

Fig-3: Shows the potential detection of microbes using disc diffusion method

\section{Amplification methods for Bacteria}

Amplification methods in staphylococci, the resistance to methicillin and cephalosporins is linked to an altered penicillin-binding protein 2a (PBP2a). Methicillin resistant Staphylococcus aureus (MRSA) is detected with excellent specificity and sensitivity by IDI-MRSA via simultaneous targeting of the staphylococcal chromosomal cassettes and a S. aureus highly conserved open reading frame, ofrX, within 1.5 $\mathrm{h}$ from having the specimen in hand. This approach utilizes a specific PCR primer coupled with a molecular beacon probe $[12,13]$

\section{Cytotoxicity or pathogenicity detection}

Different pathogens contain a variety of compounds that can be tested in order to check the status of disease at the level of infections. When pathogens enter into body, then they attack the body also blood. The specific concentrations of blood can be tested to diagnose the disease caused by specific bacteria [14]. The procedure and protocols of this method as follow by taken the $3 \mathrm{~mL}$ of blood that put into the tubes use for blood collection containing heparin to avoid the coagulation. The tubes then mix carefully in order to avoid the destruction of blood cells and finally transfer into falcon tubes that capacity to store $15 \mathrm{~mL}$ samples of respective testing. The blood samples then centrifuge for a period of 4 minutes at 900 $\mathrm{Xg}$. The supernatant catalyze by separate and cells with red blood cells primarily with phosphate buffer with a $\mathrm{pH}$ around the 7.4 for four times and heamacytometer catalyzed used for counting the RBCs [14-17].

Then samples of respective testing again ability incubate for forty minutes at $37^{\circ} \mathrm{C}$ and after ten minutes of incubation, tubes ability on the normal ice and again centrifuge at for five minutes at $1400 \mathrm{X} \mathrm{g}$. When incubation by enzymes and complete, falcon tubes containing supernatant catalyzed initially taken and catalyzed primarily with phosphate buffer. These dilutions ability principally maintain with and epidorff then finally placed on low temperature such as on ice. $100 \mu \mathrm{L}$ samples that ability taken from epidorff catalyzed put to the well plates for further analysis. The extracts incubated at $37^{\circ} \mathrm{C}$ for the 30 minutes with dilute blood suspension and centrifuged. The triton on $\mathrm{X}-100$ and phosphate buffer use as positive for complete lysis of RBCs and negative control that catalyze used for zero percent lysates respectively. Then results ability present in the form of percentage in relation to lysis of RBCs. Spectrophotometer use for taken the absorbance principally at $576 \mathrm{~nm}$. The hemolytic activity evaluate to determine the cytotoxic behavior of samples. The experiments ability repeate again for three times and results finally ability recorded. The hemolytic inhibition catalyzed basically calculated with chemical formula given below in the form of percentage [18-20]. Lysis of the RBCs (in \%) $=(\mathrm{A}$ sample - A negative Control/A positive control) X 100

\section{DNA Fragmentation in Microorganisms}

It is observed that specific breaks in DNA strands can be visualize with through gel electrophoresis as well as through comic biochemical analysis. Chromosomal DNA fragmentation also leads to breakage of DNA strands under specific conditions of temperature and other specific materials required for throe breakage. Different methods and protocols are used for DNA Fragmentation in microorganisms [21, 22].

In higher eukaryotic cells, this may be a consequence of active programmed cell death. The presence of DNA breakage is usually evaluated using biochemical or molecular procedures such as alkaline unwinding, DNA elution, gel electrophoresis, sucrose gradient sedimentation, melting curve analysis, viscoelastometry, or light scattering [23, 24]. 


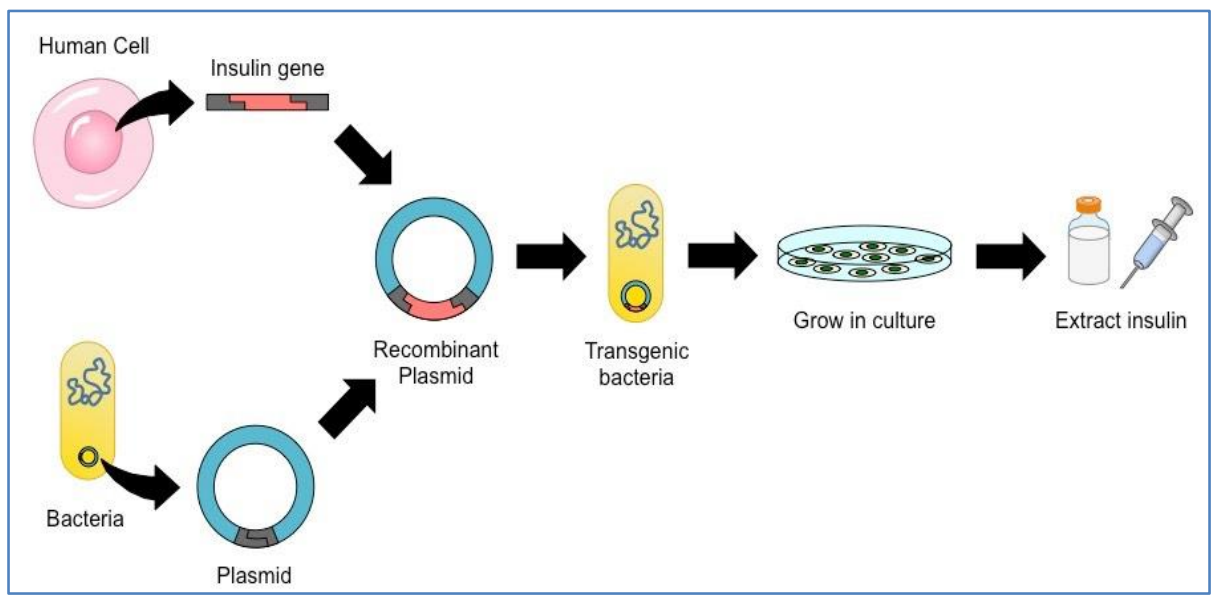

Fig-4: Shows the DNA fragmentation and production transgenic bacteria

The protocol of methods of DNA fragmentation as follows. DNA damage protection assay is used to check the concentration of microbial extract at molecular level. Blood collection tubes normally use and EDTA add in these collection tubes. Plasma the reaction and separated out from remaining samples by the process of centrifugation. DNA that obtain through the process of purification. The preparation of the phosphate buffer $50 \mathrm{Mm}$ involves the $0.18 \mathrm{~g}$ chemical compound such as $\mathrm{NaH}_{2} \mathrm{PO}_{4}$ and $0.55 \mathrm{~g}$ of another chemical compound such as $\mathrm{Na}_{2} \mathrm{HPO}_{4}$ catalyzed add to the $100 \mathrm{~mL}$ of the distilled water. Then properly catalyze shake this mixture for proper homogenization [25-28].

1X TAE buffer that prepare by mixing the 10 $\mathrm{mL}$ of the 50X TAE buffer in the distilled water that add in the amount approximately $490 \mathrm{~mL}$. Then next, $1 \%$ of the Agarose gel prepare by mixing the agarose powder of one gram to the $1 \mathrm{X}$ TAE buffer in the amount $10 \mathrm{~mL}$. Then properly shake this mixture and put it to oven in such a way that proper homogenization occurrs. The mixture then providing the cooling temperature. Ethidium bromide in the amount of $20 \mathrm{uL}$ properly add to freshly prepared Agarose gel. Then agarose gel then pour carefully to gel tank that run supplying the electricity. Agarose gel finally solidify into the gel tank. After that $1 \mathrm{X}$ TAE buffer in the proper amount catalysed added to the gel tank so that electrodes of the gel tank system ability sink into the buffer. Loading dye that bromophenol blue appears in blue colour in the amount of $3 \mathrm{~mL}$ carefully add to mixture. Then samples ability carefully taken and load to the freshly wells and electricity supply in the 100 volts approximately for 50minutes depends upon the thickness of the gel. The gel finally observe in the gel luminesce system that gives brightness to bands if the gel bright [29-33].

This method is useful to differentiate the different normal bands as compared to other bands that shrink die to oxidative stress. The normal bands in this method clearly appear visible while on the other hand, shredded bands appears blurry due to more oxidative stress and error during running the experiment $[34,35]$.

\section{CONCLUSION}

Different types of nucleic acid amplification as well as genetic testing methods such as PCR and nucleic acid identification and characterization methods, such as hybridization in the form of gene probes, RFLP analysis, and nucleotide sequencing, have been applied to the detection of microbes both at molecular and cellular level. DNA sequencing that is used to identify bacteria, molds and yeasts.

\section{REFERENCES}

1. Fierer, N., Wood, S. A., \& de Mesquita, C. P. B. (2021). How microbes can, and cannot, be used to assess soil health. Soil Biology and Biochemistry, 153, 108111.

2. Liu, H., Li, J., Carvalhais, L. C., Percy, C. D., Prakash Verma, J., Schenk, P. M., \& Singh, B. K. (2021). Evidence for the plant recruitment of beneficial microbes to suppress soil- borne pathogens. New Phytologist, 229(5), 2873-2885.

3. Becattini, S., Sorbara, M. T., Kim, S. G., Littmann, E. L., Dong, Q., Walsh, G., \& Pamer, E. G. (2021). Rapid transcriptional and metabolic adaptation of intestinal microbes to host immune activation. Cell Host \& Microbe.

4. Kiner, E., Willie, E., Vijaykumar, B., Chowdhary, K., Schmutz, H., Chandler, J., \& Benoist, C. (2021). Gut CD4+ $\mathrm{T}$ cell phenotypes are a continuum molded by microbes, not by $\mathrm{TH}$ archetypes. Nature Immunology, 22(2), 216-228.

5. Shahid, A., Ali, S., Zahra, T., Raza, M., Shahid, A., Saeed, M. U., \&amp; Javaid, F. (2020). Influence of Microbes in Progression of Cancer and DNA Damaging Effects. Haya: Saudi J. Life Sci, 5(11), 246-252.

6. Iftikhar, A., Shahid, A., Shah, S. S., Ali, S., Raza, M., Ali, E., \&amp; Umbreen, S. Antimicrobial Activities of Selected Medicinal Plant with 
Potential Role of Chemical Compounds. Saudi J. Pathol. Microbiol, 5(11), 466-470.

7. Qamar, M., Mustafa, G. A., Tariq, S., Rafeeq, H., Rafiq, M., Naqvi, W. Z., ... \& Kanwal, T. Novel Methods for Detection of Biological Samples, Current Direction and Future Perspectives.

8. Naeem, M., Hayat, M., Qamar, S. A., Mehmood, T., Munir, A., Ahmad, G., ... \& Hussain, A. (2019). Risk factors, genetic mutations and prevention of breast cancer. Int. J. Biosci, 14(4), 492-496.

9. Shafiq, S., Adeel, M., Raza, H., Iqbal, R., Ahmad, Z., Naeem, M., ... \& Azmi, U. R. (2019). Effects of Foliar Application of Selenium in Maize (Zea Mays L.) under Cadmium Toxicity. In Biological Forum-An International Journal (Vol. 11, No. 2, pp. 27-37).

10. Ahmad, I., Khan, S., Naeem, M., Hayat, M., Azmi, U. R., Ahmed, S., .. \& Irfan, M. (2019). Molecular Identification of Ten Palm Species using DNA Fingerprinting. Int. J. Pure App. Biosci, 7(1), 4651.

11. Usman, G., Muhammad, N., Hamza, R., Usman, I., Ayesha, A., Saqib, U., ... \& Fatima, Q. (2019). A Novel Approach towards Nutraceuticals and Biomedical Applications. Scholars International Journal of Biochemistry, 2(10), 245-252.

12. Tahir, M. F., Ali, S., Noman, M., \& Goher, M. A Novel Approach towards the Potential Effects of Chlorpyrifos on Testicular Biochemistry and Physiology of Male Sprague Dawely Rats.

13. Naeem, M., Ali, J., Hassan, M. Z., Arshad, B., Rao, M. H. I., Sarmad, M. S. K., ... \&amp; Hassan, M. U. (2019). Novel Approach towards DNA Barcoding as a Tool in Molecular Biologyand Biological Activities of Cyclotides with Particular Emphasizes at Molecular Level. In Biological Forum-An International Journal, 11(2), 83-96.

14. Naeem, A., Saddique, S., \& Chand, S. A. (2019). Advancement and Future Directions towards Herbal Treatment for Various Diseases.

15. Naeem, M., Ashraf, A., Safdar, H. M. Z., Khan, M. Q., Rehman, S. U., Iqbal, R., \& Ahmad, G. (2020). Biochemical changes in patients with chronic kidney failure in relation to complete blood count and anemia. IJB, 16(1), 267-271

16. Naeem, M., Hussain, A., Azmi, U. R., Maqsood, S., Imtiaz, U., Ali, H., ... \& Ghani, U. (2019). Comparative Anatomical Studies of Epidermis with Different Stomatal Patterns in Some Selected Plants Using Compound Light Microscopy. International Journal of Scientific and Research Publications, 9(10), 375-380.

17. Ahsan, M., Aslam, M., Akhtar, M. A., Azmi, U. R., Naeem, M., Murtaza, G., ... \& Shafiq, S. (2019). Effect of inoculation of three rhizobial strains on maize hybrids. Journal of Biodiversity and Environmental Sciences, 14(6), 168-177.

18. Hazafa, A., Batool, A., Ahmad, S., Amjad, M., Chaudhry, S. N., Asad, J., ... \& Ghani, U. (2020).
Humanin: A mitochondrial-derived peptide in the treatment of apoptosis-related diseases. Life Sciences, Volume 264, 2021, 118679.

19. Rafeeq, H., Ahmad, S., Tareen, M. B. K., Shahzad, K. A., Bashir, A., Jabeen, R., ... \& Shehzadi, I. Biochemistry of Fat Soluble Vitamins, Sources, Biochemical Functions and Toxicity. Haya: The Saudi Journal of Life Sciences

20. Ghani, U., Naeem, M. Bukhari, S.S.H., Yar, G., Tariq, I., Siddique, S., Nawaz, H.A., Pal, Z.A.A., Nasim, F. and Bukhari, S.A.H. (2019). Prevalence and Risk Factors associated with Hepatitis B and Hepatitis $\mathrm{C}$ and their Correlation with Inflammatory Markers among Southern Region of Punjab. Biological Forum - An International Journal, 11(2): 136-143.

21. Khan, S., Zelle Rubab, S. H., Abbas, A., Arshad, R., \& Tareen, M. B. K. Hematological profile of children with severe acute malnutrition at the Tertiary care hospital in Multan.

22. Muhammad, N., Umair, R., Azmi, S., Ahmad, Q., Ahmad, M., Tariq, M., Muhammad, A. F. (2019). Reliable vaccine production by using Risk Based Bioengineering Strategies. 6th International Conference on "Sustainable Agriculture in Changing Climate: Strategies and Management, 261.

23. Rafeeq, H., Arshad, M. A., Amjad, S. F., Ullah, M. H., Muhammad, H., Imran, R. K., ... \& Ajmal, H. Effect of Nickel on Different Physiological Parameters of Raphanus Sativus.

24. Khanom, A., Azad, M. A. K., Ali, M. M., Ali, M. Y., Biscatalysed, S. K., \& Rahman, M. M. (2021). Plants and microbes' responses to the net nitrification rates of chemical fertilizers in vegetable soils. Applied Soil Ecology, 158, 103783.

25. Yan, Z., Song, N., Wang, C., \& Jiang, H. (2021). Functional potential and assembly of microbes from sediments in a lake bay and adjoining river ecosystem for polycyclic aromatic hydrocarbon biodegradation. Environmental Microbiology, 23(2), 628-640.

26. Zhang, Y., Ryan, J. P., Hobson, B. W., Kieft, B., Romano, A., Barone, B., ... \& Scholin, C. A. (2021). A system of coordinated autonomous robots for Lagrangian studies of microbes in the oceanic deep chlorophyll maximum. Science Robotics, 6(50).

27. El-Aassar, M. R., Ibrahim, O. M., Fouda, M. M., Fakhry, H., Ajarem, J., Maodaa, S. N., ... \& Hafez, E. E. (2021). Wound dressing of chitosan-basedcrosslinked gelatin/polyvinyl pyrrolidone embedded silver nanoparticles, for targeting multidrug resistance microbes. Carbohydrate Polymers, 255, 117484.

28. Jacobson, A., Yang, D., Vella, M., \& Chiu, I. M. (2021). The intestinal neuro-immune axis: crosstalk 
Noshaba Munawar et al; Saudi J Pathol Microbiol, Apr, 2021; 6(4): 138-143

between neurons, immune cells, and microbes. Mucosal Immunology, 1-11.

29. Shah, Z., Gul, T., Khan, S. A., Shaheen, K., Anwar, Y., Suo, H., ... \& Salman, S. M. (2021). Synthesis of high surface area AgNPs from Dodonaea viscosa plant for the removal of pathogenic microbes and persistent organic pollutants. Materials Science and Engineering: B, 263, 114770 .

30. Van Teeseling, M. C., \& Jogler, C. (2021). Cultivation of elusive microbes unearthed exciting biology. Nature Communications, 12(1), 1-3.

31. Kumar, A., Padhy, S. R., Das, R. R., Shahid, M., Dash, P. K., Senapati, A., ... \& Nayak, A. K. (2021). Elucidating relationship between nitrous oxide emission and functional soil microbes from tropical lowland rice soil exposed to elevated $\mathrm{CO} 2$ : A path modelling approach. Agriculture, Ecosystems \& Environment, 308, 107268.
32. Rotaru, A. E., Yee, M. O., \& Musat, F. (2021). Microbes trading electricity in consortia of environmental and biotechnological significance. Current Opinion in Biotechnology, 67, 119-129.

33. Amrati, F. E. Z., Bourhia, M., Saghrouchni, H., Slighoua, M., Grafov, A., Ullah, R., ... \& Bousta, D. (2021). Caralluma europaea (Guss.) NE Br.: Anti-inflammatory, antifungal, and antibacterial activities against nosocomial antibiotic-resistant microbes of chemically characterized fractions. Molecules, 26(3), 636.

34. Muhammad Naeem. 2019. Principles of Biochemistry \& Biological Sciences. Nishtar Publications. Volume 1, Page 464.

35. Yeom, J., \& Groisman, E. A. (2021). Reduced ATP-dependent proteolysis of functional proteins during nutrient limitation speeds the return of microbes to a growth state. Science Signaling, 14(667). 